\title{
Could God be a necessary being? ${ }^{1}$
}

\author{
Richard Swinburne \\ [Swinburne, Richard, 2015, "Could God be a Necessary Being?", \\ Oxford Studies in Philosophy of Religion, no.6.]
}

\section{History of the Maximalist Account of Divine Necessity}

Aquinas held that God is a 'necessary being'; but all that he meant by a 'necessary being' is a being not subject to corruption, that is one whose nature is such that it will go on existing forever unless something else annihilates it. So he held that angels and human souls are necessary beings' ${ }^{2}$, but only 'conditionally necessary'. One way in which he distinguished God from other necessary beings is as one 'who does not have a cause of his necessity from somewhere else'; ${ }^{3}$ and, taken by itself, that could lead to what I shall call a minimalist account of divine necessity: God is 'necessary' because he is not causally contingent on anything else, that is he is uncaused. I myself have adopted this minimalist account in some earlier writings. ${ }^{4}$

But, at least since the seventeenth century, the favoured account of divine necessity has been what I will call the maximalist account. I shall understand by 'metaphysical necessity' the strongest kind of necessity there is, and so by 'metaphysical possibility' the weakest kind of possibility there is. A substance or event is metaphysically necessary iff it is metaphysically necessary that it exists. I shall call any proposition whose metaphysical necessity (impossibility or possibility) is discoverable by a priori reflection 'logically' necessary (impossible or possible), a term which covers both 'logical necessity' (impossibility or possibility) in a narrow sense and also 'conceptual necessity' (impossibility or possibility); the wider 'metaphysical necessity' includes also a posteriori such necessity ${ }^{5}$. On a maximalist account of divine necessity, God is metaphysically necessary in this sense. Leibniz, relying on the Principle of Sufficient Reason, claimed that to explain the existence over time of the universe, we must postulate God as 'something which is of absolute or metaphysical necessity', that is 'one in which the contrary existence implies a contradiction'. ${ }^{6}$ And so he was claiming that God is a logically necessary and so a metaphysically necessary being in my senses of these terms. And since Leibniz, most 
philosophers have assumed that theism involves the view that God is at least a metaphysically necessary being in my sense. Kant cited Leibniz's discussion and made this assumption. He went on to argue that 'we are unable to conceive what can be meant by [the] necessity [of such a being]. The concept of necessity is only to be found in our reason, as a formal condition of thought; it does not allow of being hypostatised as a material condition of existence'. ${ }^{7}$

Most subsequent philosophers have shared Kant's view; and many of them have felt that the minimalist view of God's necessity is incompatible with theism. In a well-known article J.N. Findlay argued that it would be quite unsatisfactory from the religious standpoint, if the god whom we worship 'merely happened to be wise, good, powerful and so forth, even to a superlative degree, and if other beings had, as a mere matter of fact, derived their excellences from this single source' And he went on to claim that to be worthy of worship a being must be such that 'his own non-existence must be unthinkable in any circumstances' ${ }^{8}$. By 'unthinkable in any circumstances' Findlay probably meant 'logically necessary' in my sense; but his argument only requires a necessity as strong as logical necessity, and so I shall read the crucial phrase to mean 'metaphysically necessary' in my sense. From that he concluded that there can be no God of what he assumed to be the normal theistic kind.

I know of no evidence that anyone before Anselm held a maximalist account of divine necessity or an account of the divine nature which entailed that. But I read Aquinas as giving, in one crucial phrase, an account of divine necessity intermediate between the maximalist and minimalist accounts. He wrote that God is 'per se necessarium', ${ }^{9}$ necessary through himself; that is, he was saying that not merely did God not get his necessity (in Aquinas's sense) from something else, but he got it from himself. I shall consider what he meant or ought to have meant by that in due course. Many commentators have supposed that by such phrases as that 'God is his own essence' and 'also his own existence'10, Aquinas was advocating the same view of divine necessity as Leibniz. But the context reveals that all that Aquinas meant by 'God is his own essence' is that in God there is only form and no matter; and so it follows that various other substances also are identical to their essences. And all that he meant by '[God] is his own existence' is that God does not derive his existence from anything external. ${ }^{11} \mathrm{I}$ know of no evidence that Aquinas held a maximalist account of divine necessity.

In this paper I shall argue that Kant was right - the maximalist account is implausible; and at the end I shall try to make plausible an intermediate account implicit in Aquinas. 


\section{Logical Necessity}

Since we can have no knowledge of whether a proposition is metaphysically (or logically) necessary (or whatever) except by reflecting on the meaning of the sentence which expresses that proposition, I shall assume that these modal properties belong primarily to sentences and only derivatively to the propositions expressed by them. So I shall call any sentence whose metaphysical necessity is discoverable by a priori reflection 'logically necessary'; and likewise any metaphysically impossible/possible/contingent sentence discoverable to be such by a priori reflection logically impossible/possible/contingent.

In learning a language we learn which concepts its words designate (and so what would constitute the instantiation of those concepts), and which propositions its sentences express (and so what are their truth conditions). As a result of this process we come to see by a priori reflection that there are some declarative sentences which could not be true whatever the world was like, because no state of affairs would constitute these sentences being true. The paradigm example of such a sentence is a selfcontradictory sentence (e.g. one of the form 'both pand not- $p$ '), which I shall in future call simply a 'contradiction'. We learn too, that there are some sentences which could not be false whatever the world was like, for example the negations of contradictions - 'could not be' because of the rules of the language, not because of some extra-linguistic metaphysical fact. The a priori reflection consists of reflection on the public usage of the words and sentence form involved.

We also learn to which other sentences a speaker who utters a given sentence is explicitly committed. I shall say that if in uttering ' $p$ ', a speaker is (in virtue of the public meanings of ' $p$ ' and ' $q$ ') explicitly committed to ' $q$ ', then ' $p$ ' 'mini-entails ' $q$ '. If ' $p$ ' mini-entails ' $q$ ', then the rules of the language have the consequence that ' $q$ ' is true in all states in which ' $p$ ' is true. So if ' $p$ ' mini-entails ' $q$, someone who sincerely utters the sentence ' $p$ and not- $q$ ' would not have fully understood either what ' $p$ ' means or what ' $q$ ' means, since that sentence could not but be false. Mini -entailments are one kind of entailment. A sentence ' $p$ ' entails ' $q$ ' iff ' $p$ and not- $q$ ' could not be true - in virtue of the rules of language. It is then natural to say that a sentence ' $p$ ' entails a sentence ' $q$ ' iff a speaker who asserts ' $p$ ' is (explicitly or implicitly) committed to ' $q$ '.

Systems of formal logic state the rules for certain kinds of entailment (e.g. that ' $p$ ' entails ' $p \mathrm{v} r$ '; and in doing so they seek to give precise form to entailments already recognised in ordinary language. But evidently there are innumerable entailments not yet 
captured by any system of formal logic. 'This is red' surely entails 'this is coloured', although - as far as I know - there is no system of formal logic so far articulated which allows us to express that entailment.

While logical impossibility, necessity, entailment etc are, I have suggested, to be defined in the above ways, there are various ways of showing that those definitions are satisfied. The most direct way of showing that ' $p$ entails $q$ ' in cases where ' $p$ ' does not mini-entail ' $q$ ' is to show that ' $p$ ' can be linked to ' $q$ ' by a series of minientailments, such that ' $p$ ' mini-entails ' $r$ ' ' $r$ ' mini-entails ' $s$ ',' $s$ minientails ' $t$ ' until we reach some sentence which mini-entails ' $q$ '. Less directly we may show that ' $p$ and not- $q$ ' entails (via such a sequence of mini-entailments) a contradiction. Any declarative sentence will be a subject-predicate sentence, an existential generalization, or some other one of many recognized forms of declarative sentence. It will to put the point loosely - assert something about some substance or property or event or whatever that it has or does not have some property or relation to some other substance, property etc; or that there are or are not certain substances, properties or whatever. Words have a sense in so far as it is clear what are the criteria for a substance, property or whatever to be that substance, property or whatever - they therefore delimit a boundary to the sort of substance or property it can be or the sort of properties it can have. Hence it will be inconsistent to affirm that an object picked out by some expression is of a kind ruled out by the very criteria for being that object. And the form of a sentence ' $p$ ' will exclude some alternatives and so it will be inconsistent to affirm that both it and some such alternative holds. If a sentence does not in this kind of way entail a contradiction, there seems no reason to deny that it is logically possible, and so therefore is the proposition which it expresses. However we cannot show that a sentence ' $p$ ' is logically possible by deducing all the sentences which it entails and showing that there is no contradiction among them, since any sentence entails an infinite number of other sentences. The most direct way to show that ' $p$ ' is logically possible is to show that ' $p$ ' is entailed by a more obviously logically possible sentence (or conjunction of sentences), that is that there is one state of affairs in which ' $p$ ' would be true, the description of which state seems obviously not to entail a contradiction.

Contradiction-entailing sentences include what used to be called 'category mistakes' - 'David Cameron is a prime number' or 'I had two helpings of democracy for breakfast'. To illustrate my point with the first example - 'David Cameron' as used in a normal context in today's English necessarily designates a person. Being a person mini-entails being a concrete object. Being a concrete object minientails not being an abstract object. Being a prime number mini- 
entails being an abstract object. So 'David Cameron is a prime number' entails 'there is something which is an abstract object and is not an abstract object, which is a contradiction.

A much less direct way of detecting all these a priori modal features of sentences is the method which Rawls called 'reflective equilibrium'. ${ }^{12}$ This method assumes that in learning the meaning of a sentence from examples of the circumstances in which it would be true, we may not acquire a full understanding of its truth conditions, that is in which other circumstances it would be true and in which it would be false. But we assume that the simplest account of the modal status of some kind of sentence which fits the examples from which we learn how to use it is the correct one and determines its proper subsequent application. We start with a few examples of obviously logically necessary (or whatever) token sentences of some kind (e.g, ones which state the circumstances which make the token sentence true); and suggest as an explanation of why they are logically necessary some general principle about sentences of the kind to which the particular tokens belong. We are justified in believing a suggested general principle to the extent to which it is a relatively simple principle and able to explain why many different token sentences of that kind have the logical status which it seems obvious that they do have - so long as there are no token sentences to which the principle denies the logical status which it seems obvious that they do have. In so far as the principle is justifiably believed, it allows us to resolve the logical status of some token sentence about whose logical status we are doubtful.

For an example consider the procedure whereby philosophers tried to construct a general analysis of 'knowledge', that is of 'S knows that $p$ '. They were aiming at an analysis which is a conceptual truth, and so logically necessary. Philosophers assembled many different examples of circumstances in which a sentence of this form is obviously true and other examples of circumstances in which a sentence of this form is obviously false, and then put forward a simple theory which purported to explain these results. One early analysis was that ' $\mathrm{S}$ knows that $p$ ' iff 'S believes $p, \mathrm{~S}$ is justified in believing $p$, and $p$ is true' ('justified' being understood in the internalist sense of 'probable on the evidence available to $S^{\prime}$.) But Edmund Gettier put forward examples of cases where fairly obviously $\mathrm{S}$ does not know that $\mathrm{p}$, although he has a justified true belief that $\mathrm{p}$. So various philosophers suggested different relatively simple principles from which it would follow that in these cases S did not know that $\mathrm{p}$, although in other obvious cases it did follow that $\mathrm{S}$ knows that $\mathrm{p}$; and they claimed that all sentences of this form are logically necessary truths, from which conclusions could be drawn about sentences whose logical status was dubious ${ }^{13}$. The method of reflective equilibrium enables us to determine the logical status of a 
sentence, in cases where its logical status is not evident and where using more direct methods cannot achieve agreement about this (because there is not enough initial agreement about which sentences mini-entail other sentences, or which other sentences are logically impossible or whatever.).

One very indirect way to show that it is epistemically probable that some sentence is logically possible is the following. It may be that some observed phenomena would be explained very well by some hypothesis, and so be very probable on normal criteria of what is evidence for what, if the sentence stating that hypothesis was logically possible. Thus the hypothesis that photons (the 'particles' of light) are both particulate and wave-like at the same time looks as it might be logically impossible -since particles are material bodies which travel through space, whereas waves are disturbances of something which occupies all space. But the hypothesis may be shown to be (probably) logically possible, on the grounds that if it is logically possible it can explain the various phenomena of light interference, diffraction, reflection, photoelectric effect, Compton effect etc, whereas the hypothesis that light is a particle and not a wave or the hypothesis that light is a wave and not a particle can only explain some of these phenomena. Without the supposition that light is both particulate and wavelike the occurrence of some of these phenomena would be very improbable; hence their occurrence is evidence for the truth and so the logical possibility of the hypothesis. Or someone might deny the logical possibility of a nonembodied person, yet faced with phenomena best explained by the hypothesis that there was a poltergeist (non-embodied person) in the room - e.g. handwriting being formed on a piece of paper without any visible or tangible hand writing it, etc etc. - might acknowledge the hypothesis as probably true and so probably logically possible. This kind of argument is not an argument from the logical possibility of such phenomena but from their actual occurrence (if they do occur) ${ }^{14}$.

In their beliefs about the modal status of sentences, as in almost all matters, humans are fallible. For two millennia it seemed obvious that 'there is a point through which different straight lines in a plane can be drawn which will coincide again at another point' could not be true under any circumstances. But in the nineteenth century people began to recognize that there are circumstances in which this sentence would be true; and so they withdrew their judgment that (for example) ' $\mathrm{L}$ and $\mathrm{L}^{*}$ are different straight lines in a plane passing through a point $\mathrm{P}^{\prime}$ mini-entails ' $\mathrm{L}$ and $\mathrm{L}^{*}$ will not coincide again at any other point $\mathrm{P}^{\prime \prime}$. Nevertheless, by the principle of credulity (that the way things seem to be makes it epistemically probable (in the absence of counter-reason) that that is how they are), the very fact that it seemed before the nineteenth century that there could be no 
circumstances in which such a sentence could be true was good reason then for supposing that there are no such circumstances, and so that ' $\mathrm{L}$ and $\mathrm{L}^{*}$ are different straight lines in a plane passing through a point $\mathrm{P}^{*}$ mini-entails ' $\mathrm{L}$ and $\mathrm{L}^{*}$ will not coincide again at any other point $\mathrm{P}^{\prime \prime}$

\section{A Posteriori Metaphysical Necessity}

But not all metaphysical impossibilities or necessities are logical impossibilities or necessities. In the 1970's Kripke and Putnam drew our attention to the fact that there are many sentences which are such that neither they nor their negations seem to entail any selfcontradiction, but which seem to be necessarily true or necessarily false with a necessity as strong as that of logical necessity or impossibility, but whose truth or falsity are discoverable only a posteriori. ${ }^{15}$ These sentences were said to be metaphysically but not logically, necessary or impossible. Thus, to modify an example used by Kripke to illustrate this class of sentences, suppose that in days long before people knew the geography of the Himalayas, explorers named a mountain of a certain visual appearance seen from Tibet 'Everest', and a mountain of a certain different shape seen from Nepal 'Gaurisanker', and used these names as rigid designators of the mountains. (A rigid designator' is a word which picks out the same object, however the object may change in respect of its nonessential properties.) These mountains are the same mountain; and being the mountains they are, they are - by the necessity of identity - necessarily the same mountain; and so - it seems - 'Everest is Gaurisanker' is necessarily true, with as hard as necessity as any logically necessary sentence. However - we may suppose - the explorers did not know this, and clearly would not have been able to discover its truth by mere a priori means. Hence it is not a logically necessary sentence. Similar considerations lead to the conclusion that 'Hesperus is Phosphorus' (as understood by early Greeks) or 'water is $\mathrm{H}_{2} \mathrm{O}$ ' (as understood in the eighteenth century) are a posteriori metaphysically necessary sentences.

What has made these necessary sentences a posteriori is that the sentence contains at least one rigid designator of which we learn the meaning by being told that it applies to certain paradigm things (especially substances and kinds of substances) having certain superficial contingent features, but where - we are told - what makes a thing that thing (that substance or a substance of that kind) is the essence, physical, chemical, or whatever (of which we may be ignorant) underlying those features. In ignorance of the latter, we do not fully understand what we are saying about a substance when we 
say that it is that substance or a substance of that kind, and may be unable to recognize the substance or its kind when it does not have the specified superficial features. Hence I call such designators 'uninformative designators'. Most designators however (and especially designators of properties) are not uninformative. They apply to things in virtue of their observable essential features (or are defined by words which do so) and not by any essence underlying paradigm instances of those things. Such designators are informative designators. 16

Hence there is available a definition of a sentence as metaphysically necessary (impossible or possible) iff it is logically necessary (impossible or possible) when we substitute co-referring informative designators for uninformative designators. To take Putnam's example of 'water is $\mathrm{H}_{2} \mathrm{O}$ ', when we substitute the informative designator of the stuff picked out by 'water', that is ' $\mathrm{H}_{2} \mathrm{O}$ ', the sentence reduces to ' $\mathrm{H}_{2} \mathrm{O}$ is $\mathrm{H}_{2} \mathrm{O}$ ' which is of course logically necessary. This definition will capture as metaphysically necessary (impossible or possible) almost all the examples of the 'metaphysically necessary' ('impossible' or 'possible') offered by Kripke, Putnam, and others. And I cannot see that any recent philosophical discussions of metaphysical necessity have given any reason for supposing that there are any metaphysical necessities other than ones which are logical necessities or reduce to these when informative designators are substituted for uninformative designators - apart from the purported metaphysical necessity of 'There is a God'.

\section{Implausibility of the Maximalist View, if necessity belongs primarily to sentences}

iven my understanding of these concepts together with my assumption that modal properties are primarily properties of sentences, and only derivatively of the propositions which they express, it seems fairly implausible to suppose that a (positive) existential sentence (a sentence claiming that there exists some substance of a certain kind) can be logically necessary - for to be so it would need to be such that its negation entails a self-contradiction. The negation of an existential sentence has the form 'there is no $\mathrm{x}$ such that $\mathrm{Gx}^{\prime}$ '; it claims that a certain property (or conjunction of properties) is not instantiated. The plausible suggestion that the mere non-existence of anything of some kind cannot entail a contradiction, and so no positive existential sentence can be a

necessary truth is of course is of course due to Hume ${ }^{17}$. It will hold 
whether the thing is of a concrete or an abstract kind. So the supposed necessary existential truths of arithmetic do not constitute an exception. The negation of , for example, such a supposed necessary truth as 'There are prime numbers greater than 3', 'There are no prime numbers greater than $3^{\prime}$, does not by itself entail a contradiction; it does so only when conjoined with some existential axiom of arithmetic (e.g 'There is a number 1' and 'Every number has a successor'). So my suggestion must hold also for the special case where ' $G$ ' designates any conjunction of properties of a kind supposed to constitute a definite description of God in terms of some of his essential properties e.g. 'essentially omnipotent, omniscient, perfectly good, and eternal'. But if it is not logically necessary that there be a being satisfying a certain description, it cannot be logically necessary that there be a particular being satisfying that description. So God cannot be a logically necessary being.

Anyone who claims that 'there is no $x$ such that $G x^{\prime}$ (where ' $G$ ' designates a definite description of God of the above traditional kind) entails a contradiction, will need to hold that innumerable other sentences of very different kinds to each other entail contradictions, when the rest of us hold that they are obviously logically possible. For example they will need to hold that 'Once upon a time there were no rational beings', and 'No one knows everything', and 'No one is perfectly good', and - among sentences evidently describing non-actual worlds - "The only substances are four mutually repelling steel balls', and 'No one knows what is happening outside a sphere of 1 mile diameter surrounding their body' all entail contradictions, because - if any one of them does not entail a contradiction -there would not be a God in anything like a traditional sense. Someone could show that all such sentences entail a contradiction only if they understood an enormous number of predicates - not just one or two technical philosophical terms - in different senses from the rest of us, or if they understood one or more formal terms such as 'exists', 'not', or 'all' differently from the rest of us. In view of the similarity in respect of the cognitive mechanisms and the process of language acquisition between humans who believe that God is a logically necessary being and those who don't, I do not find it very plausible to suppose that the former understand all these predicates in different senses from the rest of us. But if they do understand the predicates in the same senses as the rest of us, they will have to admit that 'there is no God' does not entail a self-contradiction, and so 'there is a God' cannot be logically necessary in the sense in which I have spelled it out.

But suppose we replace ' $G$ ' by 'G*'which is an uninformative designator of God in terms of some of his actual properties (which may or may not include such properties as omnipotence) by which we learn to refer to God, but which we do not assume to be essential 
properties of God. For after all is it not reasonable to assume that we do not know what is the essence of God? Now let ' $G$ ' be an informative designator of that unknown essence. In that case could not 'there is an $\mathrm{x}$ such that $\mathrm{Gx}^{\text {' }}$ be logically necessary without any of the sentences discussed in the previous paragraph being logically impossible? Those sentences would still be false, but they would not be logically impossible. Then 'there is an $\mathrm{x}$ such that G* $\mathrm{x}^{\prime}$ could be metaphysically necessary a posteriori; because when we substitute for ' $G$ *' the co-referring designator ' $G$ ' we get a logically necessary sentence. If we suppose that we know nothing at all about what are the essential properties of God, the earlier Humean intuition that there cannot be any logically necessary existential sentence might still seem plausible, but in the absence of the arguments of the previous paragraph it would not seem nearly as plausible as before. But we would have to suppose that the God whom we worship could suddenly become bad or too deaf to hear our prayers, or could simply cease to exist. His existence would be as precarious as our own. And that would lead us back to Findlay's objection that 'it would be quite unsatisfactory from the religious viewpoint if [God] merely happened to be wise, good, powerful and so forth.' We must suppose that God has some of the traditional properties essentially if he is to deserve worship ${ }^{18}$, and so that 'there is an $\mathrm{x}$ such that $\mathrm{Gx}^{\prime}$ entails that there is a being who has some of these properties, and so by the argument of the previous paragraph it would be implausible to suppose that 'there is a God' is logically necessary.

\section{Implausibility of the Maximalist view, if necessity belongs primarily to propositions}

Everything which I have written so far in this paper assumed that the primary bearers of modal properties are sentences; and so that talk about the modal properties of propositions is analysable as talk about the modal properties of sentences which express these propositions. But some philosophers hold that the primary bearers of modal properties are propositions which exist eternally in a timeless realm; and that talk about the modal properties of sentences is to be analysed as talk about the modal properties of those propositions which the sentences express. If that were so, then there would be good reason to believe that there exist innumerable propositions, never expressed and maybe never expressible. I do not see any good reason for believing this, and hold that talk about propositions is merely a useful fiction. We cannot interact with propositions, nor do we need to postulate them in order to explain what we observe - the behaviour of humans who utter sentences. And if the necessary 
truths were truths about eternal propositions, there would be no easy explanation of how we are in a position to know which such propositions are necessarily true. Why should we trust our intuitions about this timeless realm? ${ }^{19}$ Whereas if necessary truths are truths about human language, there is a ready explanation of how we are in a position to know about their modal status; we learn under which (if any) conditions they would be true merely by learning language.

If however we suppose that propositions are real timeless entities which have a modal status independently of any human sentences which might express them, then Hume's general intuition that for any kind of entity it is always logically possible that it does not exist is less compelling. It becomes a bit more plausible to suppose that the proposition expressed by the sentence 'there is a God' might be a logically or at least a metaphysically necessary truth- even if we assume that logically impossible propositions are ones which entail a contradiction, and metaphysically impossible propositions are ones from which we can derive logically impossible propositions by substituting co-referring informative for uninformative designators. For then we might not have any comprehension of the depths hidden within propositions. So 'there is a God' might be logically necessary , because then its negation might entail innumerable propositions which never will be and perhaps never could be expressed by humans and which would in turn entail a contradiction. This epistemic possibility will not provide us with a sound ontological argument, but it does allow the possibility of there being such an argument, unknown and perhaps unknowable by humans.

There would however still remain the difficulty of the innumerable other apparently logically possible propositions which would have to be held necessary. And there would also be an unwelcome consequence for theism. For there are innumerable logically necessary propositions, other than (if it is one) ' there is a God'; and if these are actually existing entities, it looks as if they constrain how God can act. If for example it is a necessarily true proposition that God cannot make me exist and not exist at the same time, then this constrains what God can do - not merely what we can do with the English language without uttering a necessarily false sentence. That necessarily true proposition would limit God. One way of attempting to avoid this is to claim that necessarily these propositions are ideas in the mind of God, and so part of his nature. But that raises the question why these propositions rather than any other ones (e.g. the one expressed by 'God cannot make a universe') are part of God's nature, and if the answer is that it is just a brute fact that they are, that would make God essentially a very un-simple being. Alternatively one could suppose that God has a nature such that necessarily he brings about just these necessary truths. ${ }^{20}$ But it 
appears to make no sense to suppose that it requires an act of some agent, even a timeless God necessarily having to act in this way to make it the case that 'all bachelors are unmarried' or that ' $5+7=12$ '. These propositions seem necessary, whatever any agent does. For if their necessity depended on the act of an agent, there would be a stage in creation prior to which they were not necessary (which means that they would not be necessary after all) - even if it is only a stage logically prior to the act of a timeless God. It is sometimes urged that some necessary propositions depend on other necessary propositions for their necessity - for example ' $2+1=3^{\prime}$ would not be necessary unless ' $1+1=2$ '. But even if that were so, and so all of a whole set of necessary truths depend on some initial members of the set for their necessity, the whole set would be necessary, whatever any agent might $\mathrm{do}^{21}$.

Yet if we are forced to suppose that God is essentially a very unsimple being, that it would be a very unwelcome result for theism, because it would deprive us of any good probabilistic arguments form observable phenomena for his existence - which in my view are by far the most cogent arguments for his existence. For such arguments claim that God provides the most probable explanation of some phenomena (e.g. the most general features of the universe, such as its conformity to laws of nature which lead to the evolution of humans.) Yet there are always innumerable possible complicated hypotheses which could be constructed which would lead us to expect the most general features of the universe - e.g polytheism, or a hypothesis which postulates that each fundamental particle behaves in the same lawlike way without there being any simple cause of this. But it is always the simplest hypothesis which leads us to expect some phenomena which is the one which is most probably true. So if God has to be a very un-simple being if he is to be a metaphysically necessary being, and I am right in supposing that by far the best arguments for his existence must claim that he is a very simple being, we would have far less reason to believe that there is such a God than we would have otherwise ${ }^{22}$. So for all these reasons I reject the maximalist account of divine necessity.

\section{Defence of an intermediate view of Divine Necessity}

But the question then re-emerges as to whether God could be a necessary being in a sense less strong than the maximalist sense, but stronger than the minimalist sense, and a sense strong enough to make it the case that God deserves worship. In order to introduce an intermediate sense of necessity, I need to make an assumption which, though controversial, is - I hope - fairly plausible, but which 
there is not space to defend adequately in a paper devoted to a different topic. This is the assumption that backward causation (an effect preceding its cause) and simultaneous causation are both metaphysically impossible ${ }^{23}$. I suggest that we could not possibly understand the notion of an event being past except as involving it being necessarily causally unaffectible, or of it being future except as involving it being possibly causally affectible. Thought experiments which purport to make the notion of backward causation intelligible describe a situation where events happen at various times defined by their temporal relation to the present, and then suggest that different suppositions about which events cause other events are compatible therewith. But we lose our grip on what it is for some type event (i.e. one described by what happened but not when it happened) to be past, if we suppose that, although it is past, it is still metaphysically possible that we could cause it to happen or cause it not to happen. Our situation is rather that at any time we can divide metaphysically possible type events into (1) those which are then fixed (metaphysically beyond our ability to cause or prevent, however powerful and free we are), and (2) those which are then not fixed (i.e. ones which we could cause or prevent, if we were sufficiently powerful and free). All events in group (1) are past, all events in group (2) which do not include as a part any event in group (1) are future. Those in group (2) which do include such a part are present events. We thus get our understanding of past, present, and future in a package with our understanding of causability. Backward causation is then clearly impossible, and so is simultaneous causation in the form of a cause causing an event to occur at exactly the same time as the act of causing. (An act of causing during the earlier part of some event could of course cause the later part of that event.)

Now God, like every other substance, is supposed to have certain essential properties such that if he lost any of these he would cease to exist. In the case of God, these include such properties as omnipotence, omniscience, and perfect freedom, from which I assume that all the other traditional essential divine properties (including perfect goodness) can be deduced apart from the property being discussed in this section. I assume that it is logically possible that there is a being with such properties. ${ }^{24}$. And so, contrary to Findlay, the theistic hypothesis has the coherent consequence that God does not 'merely happen to be wise, good, powerful and so forth, even to a superlative degree'. A being with these essential properties and/or most of the other traditional properties of God could - it is metaphysically posssible - exist for only a limited time. But God is supposed to be also essentially eternal, which I shall construe for the moment as essentially everlasting - I shall consider later the possibility of God being timeless . Now there can be no problem with 
essential forward everlastingness; this is just essential incorruptibility. Because a cause precedes its effect, a being can influence its own future; and if he is powerful enough, he can be the sole determinant of his future, and be so constituted that he causes himself to go on existing forever. But essential backward everlastingness is a strange property. Even if the present nature of some substance determines the kind of past it can have had - if it had a past, it seems that any substance other than God (as he is supposed to be) could - it is metaphysically possible - have come into existence at any time ${ }^{25}$.

However God is supposed to have another property, which it is I suggest - logically possible that a being with the other abovementioned divine properties could possess at some time; and that is that part of the property of being necessary in the minimalist sense, which consists in not being caused (to any degree) to exist by anything else; and together with it, the property of not existing as a result of chance (that is, of not existing at any time without there being any cause of this existence). And it is also - I suggest - logically possible that a being possess that property (of not being caused to exist by anything else or by chance) essentially. There could be a being which was essentially so great that it could not exist at any time if it were at that time dependent on anything else, or dependent on chance for its existence. Then, since it could not be caused to exist by anything else nor by chance, that is by nothing, it could only exist if it were caused to exist at each moment of its existence by itself. This being would have the property of essential aseity. Given my assumption of the necessary priority of cause to effect, this means that its existence at each moment of time would be (fully) caused by and so dependent on its own existence at each earlier moment of time. ${ }^{26}$ From that it follows that the being would be essentially backwardly everlasting. It is because all beings of other kinds known to us do not have aseity, let alone essential aseity, that they could have come into existence at any time. Finally let us understand by a being being omnipotent, not merely that he is such that he can do anything metaphysically possible to do, but so that 'doing anything metaphysically possible' includes causing the existence or non-existence of any substance whatsoever. That rules out the possibility of there being any other substance which has essential aseity. My claim is that it is logically possible that there be a being which has all the other traditional divine properties (with omnipotence understood as above) and also essential aseity.

One reason for believing this claim to be logically possible is that it seems to me and I hope to others to be logically possible, and so - by the principle of credulity -we should believe that it is. I do not think that I can show that this claim is logically the very indirect probabilistic method of showing this is available. The hypothesis that 
there is such a being will - if it is a logically possible hypothesis, and if arguments of a kind which I and others have given elsewhere ${ }^{27}$ make it probable that we will find a universe of the kind we do find. This explanation is available to explain not merely the present and future of that universe, but its past for however long it has existed; and it will be the simplest possible ultimate explanation of all else that there is and all that there could (metaphysically) be, apart from itself. That makes it epistemically probable that the hypothesis is true and so logically possible ${ }^{28}$.

So I suggest that we can understand God being a necessary being in the sense that he has essential aseity. If he exists at any time, (of metaphysical necessity) there is a total cause of his existence at that time - himself at an earlier time. And since there can be no time before all time - given the necessary priority of causes to effects - it is not logically possible that such a being ${ }^{29}$ could have a cause of his existing throughout all time, that is existing at all; and so it makes no sense to ask for an explanation of that. The postulated God is so great that no other substance could exist unless caused to exist by him. His necessity is, as Aquinas claimed, per se; he is necessary because (at each time) he is causally necessitated to exist by himself. God is causa sui. In that case, if God exists, it would -contrary to Findlay - not be 'a mere matter of fact', that 'other beings derive their excellences from this single source'; it would not have been causally possible (at any time) for them to have derived them from anywhere else.

Aquinas would not of course have endorsed my account of how this comes about - as a process in time; for Aquinas claimed that God is timeless; God exists in his one timeless moment and timelessly causes all that happens as it happens. Now if that were a logically possible hypothesis, which I do not believe it to be, then God would cause effects by a kind of causation which is not the causation of a later effect; it is in God's timeless moment what Stump and Kretzmann called 'co-occurrent' causation which seems from God's viewpoint to amount in effect to simultaneous causation ${ }^{30}$. If simultaneous causation were logically posssible, then God could in his timeless moment cause his own existence. And that is why Aquinas does not have to claim merely that God 'does not have a cause of his necessity from somewhere else', but may claim that God has this cause from himself - which, despite his explicit denial that God is the cause of himself ${ }^{31}$ - seems implicit in his claim that God is per se necessary. So whether we hold that God is essentially everlasting or essentially timeless, that God is causa sui is an intelligible claim (given, in the case of the 'timeless' hypothesis, that it and its kind of simultaneous causation are intelligible hypotheses). And on the hypothesis that God is essentially everlasting, that God is 
causa sui is needed to explain how God can be essentially backwardly everlasting.

So on both hypotheses there is an explanation of why there is a God (on the 'everlasting' hypothesis at each and every moment of time) ; there is a God because God caused there to be a God, and he could not not have caused there to be a God. God does not exist 'by chance'. He is worthy of worship, not merely because as a matter of fact he is the actual cause of all other things, but because - given the ultimate principles governing the universe, that is given God nothing else could have existed without him. It remains the case however, given my earlier arguments, that God's 'own non-existence' is not 'unthinkable in any circumstances'. But he is a necessary being in a sense intermediate between the minimalist sense that he is uncaused, and the maximalist sense that his existence is metaphysically necessary, the sense that he is necessary because he is (of metaphysical necessity) causally necessitated to exist, that is caused to exist, by himself. 


\section{NOTES}

1.This paper contains (in sections II, III, IV, and V) a shortened version of material from an earlier paper, 'What kind of necessary being could God be?' in European Journal for Philosophy of Religion, 4 no.2 (2012), 1-18; , published also in (ed.) M. Szatkowski, Ontological Proofs Today, Ontos Verlag, 2012. That paper was concerned simply to refute what I call in the present paper the 'maximalist' account. The present paper goes on to advocate a different view of divine necessity, implicit in some of what I have to say about this in my The Coherence of Theism, revised edition, Oxford University Press, 1993, but not sharply distinguished from what I call the minimalist account.

2. For angels, see the implication of Summa Theologiae Ia,50.5ad3. For human souls, see the implication of op. cit Ia.75.6ad2.

3. op.cit.Ia.2.3. My quotations from Aquinas's Summa Theologiae are taken from the Blackfriars edition, 1964-

4. See for example The Coherence of Theism, p. 277: 'To say that God is necessary...is to say that God does not depend for his existence on himself or on anything else'.

5. This definition of 'metaphysical necessity' picks out the kind of necessity discussed by Saul Kripke in his discussion of 'necessity' in his Naming and Necessity, republished by Blackwell Publishing, 1981; he writes there that his concern with that kind of necessity is a concern with 'a notion... of metaphysics' ( $p$. 35). Alvin Plantinga thought of there being two kinds of 'logical necessity', 'narrowly logical' and 'broadly logical', which together seem to constitute metaphysical necessity in my sense. See Plantinga, The Nature of Necessity, Oxford University Press, 1972, pp. 1-2. Plantinga's terminology has been adopted by others, but the line between the 'narrowly logical' and 'broadly logical' seems to be drawn in different places by different writers; and so I make no apology for defining 'logical necessity' in my own way which does in fact correspond to much earlier usage.

6. 'On the Ultimate Origin of Things' in Leibniz: Philosophical Writings, translated by Mary Morris, Everyman, 1934, pp. 32-3.

7. I. Kant, Critique of Pure Reason B648. Translated by N. Kemp Smith, Macmillan and Co, 1964.

8. J.N. Findlay, 'Can God's Existence be Disproved?', Mind 57 (1948), 176-83. His italics. It is because Findlay wrote before a posteriori metaphysical necessity had been recognized, that I assume that by 'unthinkable in any circumstances' he meant 'logically necessary'.

9. op. cit. Ia.23.

10. op. cit. Ia.3.4.

11. Aquinas seems to claim elsewhere (in effect) that only selfcontradictions are absolutely impossible, when he writes that 'the impossible is that in which the predicate is incompatible with the subject' (op.cit. Ia. 25.3.) That might seem to suggest that he thought that the negation of 'there is a God' entailed a contradiction, and - in a certain sense of 'entails' which is not our normal sense - so he did. But that was because he thought that anything incompatible with what was already fixed entailed a contradiction; on his view what is 'absolutely possible' changes with time. But God, as the eternal source of 
everything, is always fixed, and so -by Aquinas's criteria- his nonexistence is always impossible, and that is why he is absolutely necessary. (I am indebted for this analysis of Aquinas's understanding of modal concepts to Brian Leftow. See his paper 'Aquinas, Divine Simplicity, and Divine Freedom' in (ed.) K.Timpe, Metaphysics and God, Routledge, 2009, esp. pp.23-29.) But this is not 'necessity' in Leibniz's sense in which a proposition 'entailing a contradiction' is something intrinsic to the proposition, and independent of what is or is not already 'fixed' outside the proposition

12. John Rawls, A Theory of Justice, Oxford University Press, 1972, p. 20. For Rawls this was a method of determining which moral principles are correct, but it can be applied to determining which sentences are logically necessary or whatever.

13. See for example Noah Lemos, A Introduction to the Theory of Knowledge. Cambridge University Press, 2007, ch. 2 for an account of various different analyses of knowledge and the various counter examples which have been used to refute them.

14. I discuss this type of argument in The Coherence of Theism, revised edition, 1993, Oxford University Press, pp. 48-50.

15. Saul Kripke, Naming and Necessity, published as a book, Blackwell, 1980; and Hilary Putnam, "The meaning of "Meaning"' republished in his Mind, Language, and Reality, Philosophical Papers, vol. 2, Cambridge University Press, 1975. I am interpreting the claims of Kripke and Putnam about necessity etc. as claims about the necessity of sentences. Kripke makes it clear that his concern is with sentences, and writes that he has no 'official doctrine' of how his account applies to 'propositions' (op. cit. pp. 20-21.)

16. For a more precise account of this distinction between 'informative' and 'uninformative' designates see my Mind, Brain and Free Will, Oxford University Press, 2013, pp. 9-22.

17. 'There is no being..whose non-existence implies a contradiction' - D. Hume, Dialogues Concerning Natural Religion, Part 9.

18. Although the Eastern Orthodox theological tradition has normally held that humans could never know what is the 'essence' (ovoía) of God, it has also normally insisted that we do know some of the 'energies' of God, which are inseparable from God and so (in my terminology) properties entailed by the divine essence, and so (in my sense) essential properties of God.

19. For these objections to the necessity of propositions of mathematics, see P.Benacerraf, 'Mathematical Truth', originally published in Journal of Philosophy, 70 (1973), 661-79.

20. See for example Thomas Morris and Christopher Menzel 'Absolute Creation' in (ed.) T. Morris, Anselmian Explorations, University of Notre Dame Press, 1987, pp. 161-172.

21. Brian Leftow's very thorougly argued recent book (God and Necessity, Oxford University Press, 2012) defends the view that some necessary truths are made true by the divine nature - for example the truths about the kind of being which God is, and also the truths of logic and mathematics; whereas other necessary truths are brought about by the will of God-for example the truths about which kinds of things (e.g red things or quarks) are metaphysically possible, and what natures 
individuals have (e.g whether Socrates is human.) My arguments in the text count against his accounts of the source of the necessity of both these kinds of propositions.

22. For my account of such arguments, and why their cogency depends on the assumption that God is a very simple being, see my The Existence of God, second edition, Oxford University Press 2004.

23. For fuller argument than I give in this paper, designed to show that both backward and simultaneous causation are impossible, see my 'Time and Causation', American Philosophical Quarterly, forthcoming.

24. See The Coherence of Theism, Part II. A rewritten second edition of this book, currently in preparation, will include a revised account of omnipotence which takes account of cogent objections to my original account of this concept. This revised account of omnipotence will also be published in an article 'God's Omnipotence' in a collection of papers on infinite properties presented at a conference at Bochum in August 2013.

25. Kripke (op. cit. p.113) claimed that (of metaphysical necessity) a human must have been born of the parents from which she was in fact born. That seems to me implausible. I could have been made yesterday in a laboratory with different genes or been born of quite different parents from my actual parents and had quite different genes from my actual genes. See my Mind, Brain, and Free Will chapter 6.

26. Given that events occur over periods of time and not at instants, and that time is continuous and not discrete, this must be phrased more precisely as follows: 'its existence during any period of time beginning at an instant $t_{1}$ and ending at an instant $t_{2}$ would be dependent on its existence during every period beginning at some instant $t^{*}$ earlier than $t_{1}$ and ending at an instant $t^{* *}$ earlier than $t_{2}$.

27. For these arguments, see the reference in note 22.

28. This is in essence the structure of the argument for the logical possibility of a God necessary in something like my intermediate sense (but not spelled out in the way done in this article), in The Coherence of Theism, Part III. For a more up-to-date justification of the simplicity of this hypothesis see my 'God as the Simplest Explanation of the Universe' in (ed.) A.O'Hear, Philosophy and Religion, Cambridge University Press, 2011.

29. By contrast, on the theist hypothesis, if the universe has existed for ever, there is still an explanation of its everlasting existence by God causing it (at each earlier moment) to exist at each (later) moment of everlasting time and so throughout all time. The difference from the case of God existing forever, is that God's existence at any time is caused by himself at an earlier time, whereas the universe's existence at any time is not caused by itself at an earlier time, but is caused by God's action at an earlier time. See The Coherence of Theism, pp.26971.

30. See E.Stump and N.Kretzmann, 'Eternity', Journal of Philosophy, 78 (1981) 429-56, call such 'co-occurrence' 'ET-simultaneity'. Despite their denial that 'co-occurrence' is the same as simultaneity, it seems to amount to that, since it is the relation which relates God's one moment to all events in human time when he is 'present' to them. 
Could God be a necessary being?

31. 'It is clear that God cannot make God' - Summa Contra Gentiles 2.25.17. (Translation from the edition published by Image Books, 1956, under the title On the Truth of the Catholic Faith.) Aquinas goes on to remark that 'it is of the essence of a thing made that its own being depends on another cause'. But it would seem - contrary to Aquinas that for so many other substances a major cause of their existing at some time is themselves existing at an earlier time. 